\title{
Interphalangeal Joint 5 of the Hand
}

National Cancer Institute

\section{Source}

National Cancer Institute. Interphalangeal Joint 5 of the Hand. NCI Thesaurus. Code

C114193.

A ginglymoid (hinge) synovial joint between the phalanges of the fifth digit of the hand. 